\title{
Comparison of Different Hydrodynamic Characteristics of Air-Water System using Dissimilar Motionless Mixers
}

\author{
Mazhar Hussain ${ }^{1}$ \\ ${ }^{I}$ Department of Chemical Engineering, Sharif College of Engineering \& Technology, Lahore, Pakistan \\ Correspondence Author: Mazhar Hussain (drmazharhussain08@yahoo.com)
}

Received September 27, 2020; Revised August 18, 2021; Accepted September 12, 2021

\begin{abstract}
The hydrodynamic characteristics of mixing fluids are always the points to consider in improvement of their mixing quality especially using motionless mixers normally stated as "Static Mixers". Motionless mixing technique was adopted for Air-Water system with the advantage of negligible power consumption over dynamic mixers. New static element "Baffle-Type Static Element" was introduced and kept under the experimentations with which different hydrodynamic characteristics were experimented and were compared to those of already used in recent studies. Dissolved Oxygen (DO) content, static mixer geometry (i.e., Baffle, Blade, Wheel, Plate and Needle), mixing fluids flow rates were chosen as variables and selected in this content as rate of mass transfer study which founds out to be significant using Baffle-Type static element. volumetric mass transfer was also achieved at higher scale which gives a clear indication of increase the mass transfer coefficient in between the comparison of Baffle-Type element and other mentioned elements. Pressure droplet and depletion in air bubble size across static elements were visually perceived using Hg-Manometer and still photography respectively. A mathematical model was also developed portraying the air bubble diameter at different flow rates for this system. Other hydrodynamics like higher DO Content, less power consumption were also found to be more advantageous for Baffle-Type static element. The novelty of this study was to introduce the advantages of using Baffle-Type static element as compared to the hydrodynamic characteristics of other elements available in the literature.
\end{abstract}

Index Terms: Baffle-Type Static Element, Power Consumption, Mass Transfer Coefficient, Pressure Drop, Depletion of Air Bubble Size.

\section{INTRODUCTION}

Mixing hydrodynamics always comes along with the 'Power Consumption' as a control parameter which normally influencing the 'Efficiency of the System'. The most efficient system consumes the maximum internal kinetic energies of mixing fluids with very less use of external power source. Motionless mixers normally stated as 'Static Mixers' are counted under those systems which utilize the kinetic energy of mixing fluids. These mixers once used in replacement of power mixers becomes more economical in the process industries of blending, dispersion and many others which does not require any complex designing too. The capability of the usage of these static mixers at higher temperatures makes them more eligible to be used in many major applications of process industries like extruding, spinning etc. for the homogenization of polymers at elevated temperatures.

The continuous advancement in static mixing methodology has been witnessed since 1965 but there is an exponential advancement in this field from 2007. In 2007 an author and researcher studied and experimented different design modifications to different static elements used for turbulent mixing of the fluids [1].

In the year 2009 a group of researchers studied and experimented Liquid-Liquid dispersion coefficient and pressure drop by mixing the fluids at higher Reynold's number using 'Sulzer SMX Static Mixer' [2].

An author along with his associates investigated the Gas particle dispersion and the effect of Gas particle velocity on it, the year was 2010. Overall, he presented the tabular form data in which different hydrodynamics characteristics for Air-Water system was tabulated using 'SMX Static Mixer' [3].

Experimental investigation was done by some researchers in 2011 to determine the volumetric mass transfer, pressure drop and interface area in a multi-scale micromixer with complex geometry [4].

A researcher Theron along with fellow companions in 2011 compared the emulsification characteristics of different static elements used for mixing the fluids under turbulent flow regime [5].

Researchers in 2013 introduced spacers for static mixers for spiral wound modules [6].

An author and researcher along with his associates in 2015 investigated the mass transfer and pressure drop with gas used as a mixing fluid for continuous phase and determines other hydrodynamic characteristics using static mixing methodology [7]. 


\section{EXPERIMENTAL SETUP}

This study was carried out in order to increase the mixing performance of Air-Water system. Hydrodynamic characteristics study was done on an experimental setup with the introduction of 'Baffle Type' static element inside the static mixing setup and same were compared by using the other static elements already in use in recent studies (i.e. Blade, Wheel, Plate and Needle) as shown in Figure 1.

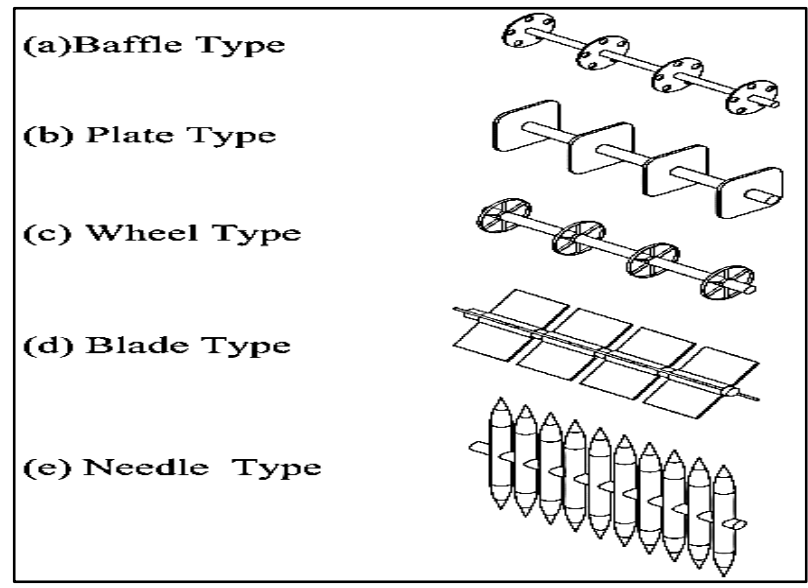

Figure 1: Types of Static Elements used in the Study

The experimental setup, as shown in Figure 2, consists of very basic elements of 'Static Mixing System' which contains the main pipe of Perspex factual of $80 \mathrm{~mm}$ diameter. Inside the main tube the static elements were placed at equal distance in order to study the different hydrodynamic parameters. $\mathrm{Hg}$-Manometer was used in between the sampling points to measure the reduction in pressure across the static element. Circulation of water through the complete cycle was done by a centrifugal pump for which the flow rate was measured through a water rotameter (measuring capacity from 1000 to 4400 $\mathrm{gal} / \mathrm{hr})$.

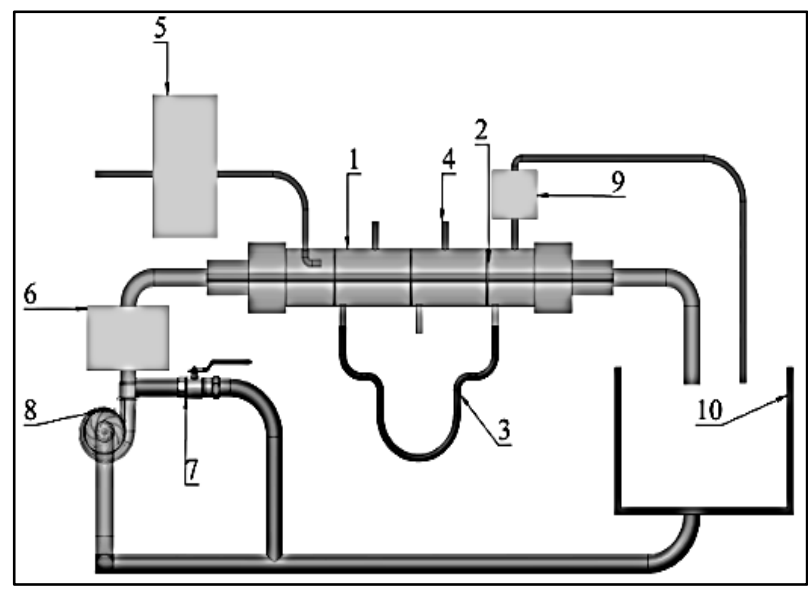

Figure 2: Experimental Rig (1) Main Static Mixing Pipe, (2) Static Mixing Element, (3) Mercury Manometer, (4) Data Sampling Points, (5) Air Flow Measuring Device, (6) Water Flow Measuring Device, (7) Pump By Pass, (8) Centrifugal Pump, (9) Bubble Visualizing Cell, (10) Water Storage Tank

Compressed air from the leading edge of the tube was induced inside the system in the form of air bubbles for which the flowrate of the air was measured through an 'Air Flowmeter' (measuring capacity from 5 to 20 lit/min). A bubble visualizing cell installed at the tail end of the main tube was used in order to have the air bubble size depicting the content of mixing done inside the tube through static elements.

The main element designed and used in this study was Baffle-Type static element, as shown in Figure 3, in which the 5 holes each of $12.7 \mathrm{~mm}$, equidistant from each other over the circumference of the element was taken into experimentation for enhancing the hydrodynamic characteristics. And then was further compared for hydrodynamic characteristics with other geometry of elements as shown in Figure 1. The hole diameter was decided after the series of experimentation with variable diameters after which $12.7 \mathrm{~mm}$ diameter was finalized in which the maximum dispersion of air bubbles was recorded which depicts the rate of mass transfer.

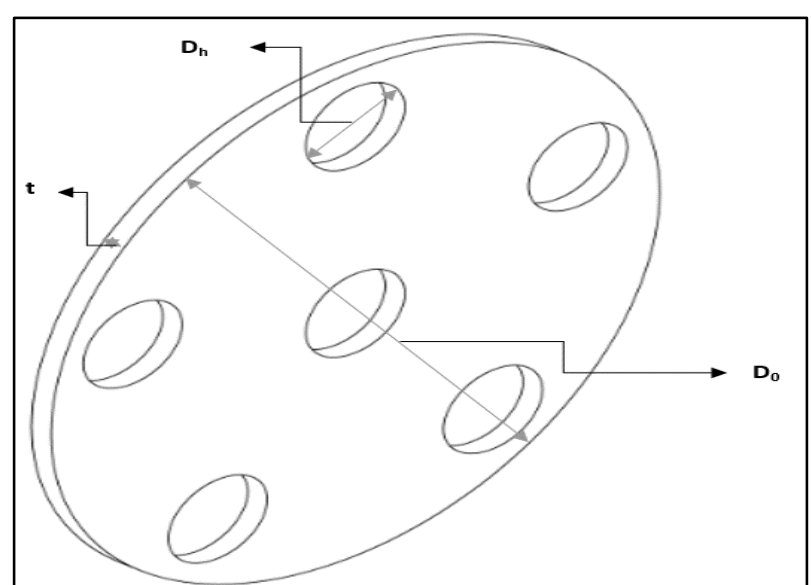

Figure 3: Baffle-Type Static Element (Do)- Outer Diameter of Elemen $=78 \mathrm{~mm}$, $(\mathrm{Dh})-$ Hole Diameter $=12.7 \mathrm{~mm}$, $(\mathrm{t})$-Thickness of Element $=$ $5 \mathrm{~mm}$

Through experimentations, below mentioned hydrodynamic characteristics of the Air-Water system were analyzed:

i. Pressure drop of mixing fluid across each element which indicates the extent of reduction in air bubble size inside water.

ii. Air bubbles sizes at different flow rates of fluid using different Static elements. "The bubbles were captured in the Bubble Visualizing Cell" as shown in figure 2 after which the average size of the bubble was measured against variating flow rates of the fluids.

iii. Mass Transfer Coefficient $\left(\mathrm{K}_{\mathrm{L}} \mathrm{a}\right)$ of the system experimented at different velocities of the mixing fluids and generated the system equation of the $\mathrm{K}_{\mathrm{L}} \mathrm{a}$ using the sets of data generated through experiments.

\section{RESULTS AND DISCUSSIONS}

\section{A. Pressure Reduction Across the Static Elements}

One of the most influencing parameters considered for hydrodynamics is reduction in pressure of mixing fluid across the static elements. As shown in Figure 2, a HgManometer installed in between the $1^{\text {st }}$ and $3^{\text {rd }}$ element was used to calculate the pressure drop across 3 static elements. From the series of experiment sets conducted, the direct influence of flow rate of stream was observed 
with the reduction in pressure. Figure 4 shows a comparative study of drop in pressure of the flow using Baffle-Type static element with the other systems profound in literature.

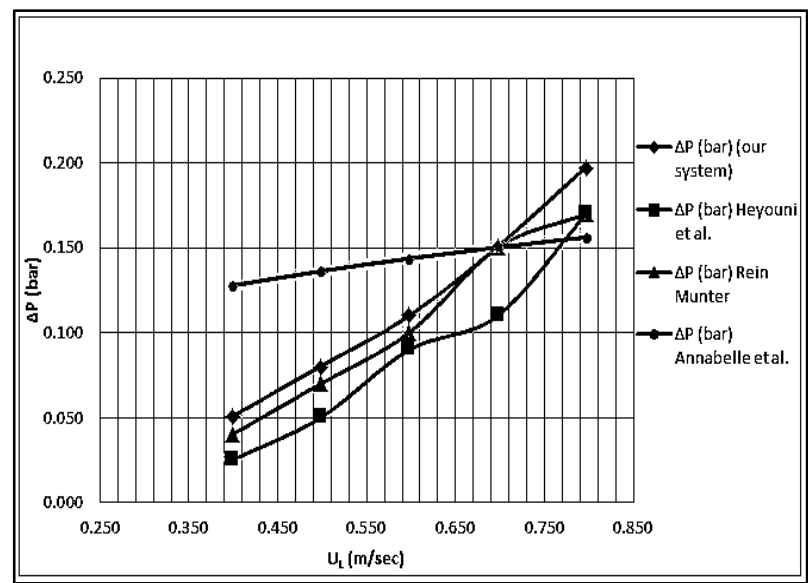

Figure 4: Drop in Pressure of Flow using Baffle-Type Static Element in comparison with that of others Available in Literature

Figure 4 shows the comparison of pressure drop of the stream across Baffle-Type static elements and other Lightnin mixers [8-10].

From the results it is evident that the Baffle-Type element causes more pressure drop across its sides which clearly indicates more mass transfer on both of its sides due to its symmetrical geometry.

\section{B. Dissolved Oxygen (DO) Content / Air Bubble Size:}

The visual representation of mass transferred from secondary fluid to primary fluid is considered as the content of Dissolved Oxygen (DO). The oxygen content dissolved into the fluid was determined through the same as reported by author Turunen, and associates [11].

Fluid samples were collected through the sampling points as shown in Figure 2, and 'Chemical Analysis' technique was applied on them to determine the DO content of the flowing fluid. A comparative study was done between Baffle-Type static element with other static elements for DO content as shown in Figure 5.

From Figure 5, it is evident that the DO content for Baffle-Type static element comes out to be far more than other elements used in this study. The higher DO content for Baffle-Type element is due to the rapid bubble breakage on both sides of the Baffle-Type element as the element is of symmetrical geometry in comparison with other elements. In addition to the symmetrical geometry, the other factors for higher DO content is because of more area available for air bubble to disperse into the water as the element contains 5 holes equally spaced from each other.

As discussed before, the static elements were experimented by installing them at right angle $\left(90^{\circ}\right)$ with pipe diameter, however, the DO content of the system can be varied at different angles of the static element. For Baffle-Type static element, the DO content can be increased if the elements are installed at $72^{\circ}$ with the pipe diameter. Table 1 shows the optimal combinations of flow rates to attain the optimum DO content within the system specifications.

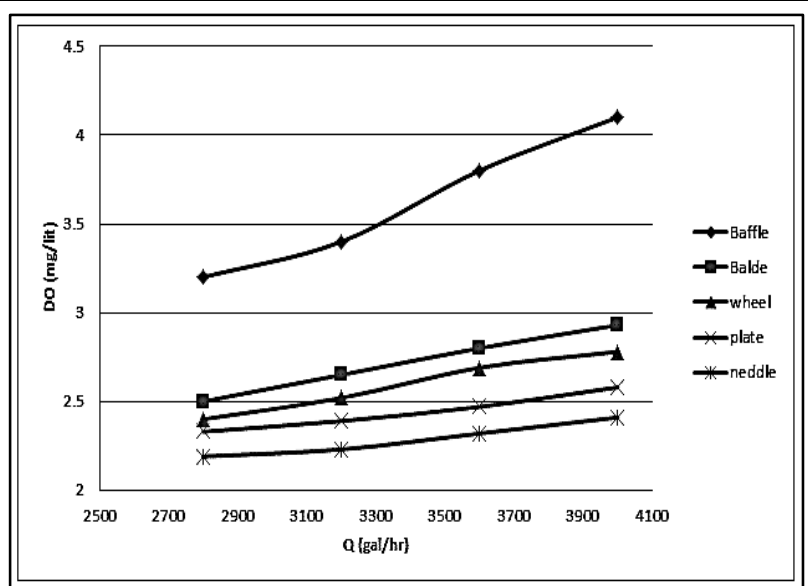

Figure 5: Comparative Study of DO Content between Baffle-Type Element with others Used in the Study

Table 1: Comparison of DO Content of Flow Using Baffle-Type Static Element with that of others Used in the Study

\begin{tabular}{|c|c|c|c|}
\hline \multirow{2}{*}{$\begin{array}{c}\text { Type of Static } \\
\text { Element }\end{array}$} & Do Content & \multicolumn{2}{|c|}{$\begin{array}{c}\text { Optimum Flow Rates } \\
\text { Combination }\end{array}$} \\
\cline { 3 - 4 } & (mg/lit) & $\begin{array}{c}\text { Water } \\
\text { (gal/hr) }\end{array}$ & $\begin{array}{c}\text { Air } \\
\text { (lit/min) }\end{array}$ \\
\hline Baffle & 4.12 & 3900 & 20 \\
\hline Blade & 2.6025 & 4000 & 15 \\
\hline Wheel & 2.416 & 3600 & 20 \\
\hline Plate & 1.8575 & 3600 & 22 \\
\hline Needle & 1.67 & 3200 & 29 \\
\hline
\end{tabular}

Likewise, the air bubble size diameters were measured, as the visual representation of higher DO content is the depletion in air bubble size. As the DO content increases in the system, the air bubble diameter tends to reduce. Air bubbles were captured in bubble visualizing cell installed at the tail end of the main pipe, as shown in Figure 2, from the data collected through the number of still images it was apparent that the air bubble diameter reduces as the flow rate of the fluids are increased. Figure 6 shows the same, in which the air bubble diameters are shown in reducing trend with the increase in flow rate of the fluids using Baffle-Type static element.

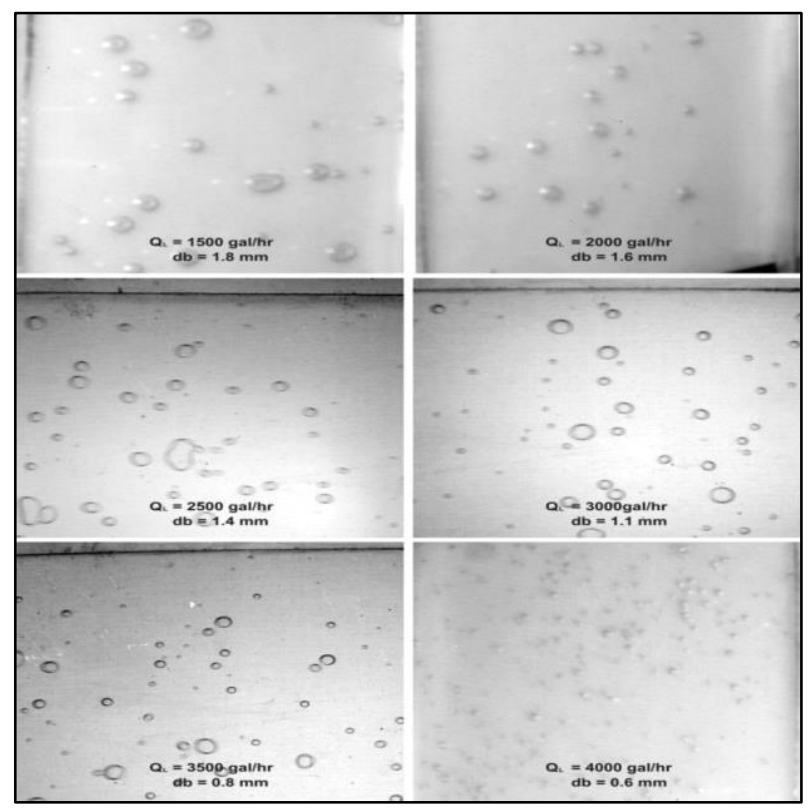

Figure 6: Still Images of Average Bubble Size of Air Bubbles using Baffle-Type Element at Different Flow Rates 
The set of data of air bubble size using Baffle-Type element was compared with that of the system used by some researchers. Figure 7 showing the comparison of bubble size of the air using Baffle-Type static element with that of the system adopted by proposed system and depicting that the Baffle-Type element reduces the air bubble size more than that of other due to the higher DO content and mass transfer [12].

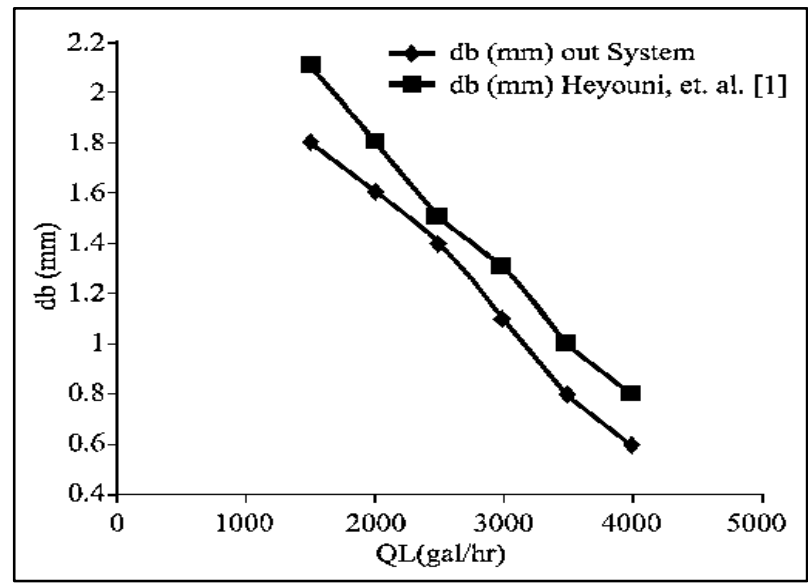

Figure 7: Air Bubble Diameter Comparison using Baffle-Type Element with the System Adopted by researchers and associates [12]

\section{Mass Transfer Coefficient $\left(K_{L} a\right)$}

The extent of mixing of one fluid into another is normally categorized as Mass Transfer Coefficient or $\mathrm{K}_{\mathrm{L}} \mathrm{a}$. To determine the same for the system studied, by Turunen, and associates. The method was adopted in which secondary fluid was nitrogen with water as primary fluid. Generally, the reduction in air bubble diameter tends to the increase in mass transfer between the fluids. So, the general parameters of the system like velocities of water and air founds to be the impacting on the Coefficient Of Mass Transfer or $\mathrm{K}_{\mathrm{L}}$ Eq. (1) [13].

$$
\mathrm{K}_{L} \mathrm{a}=\mathrm{K} \times V_{L}^{a} \times V_{G}^{b}
$$

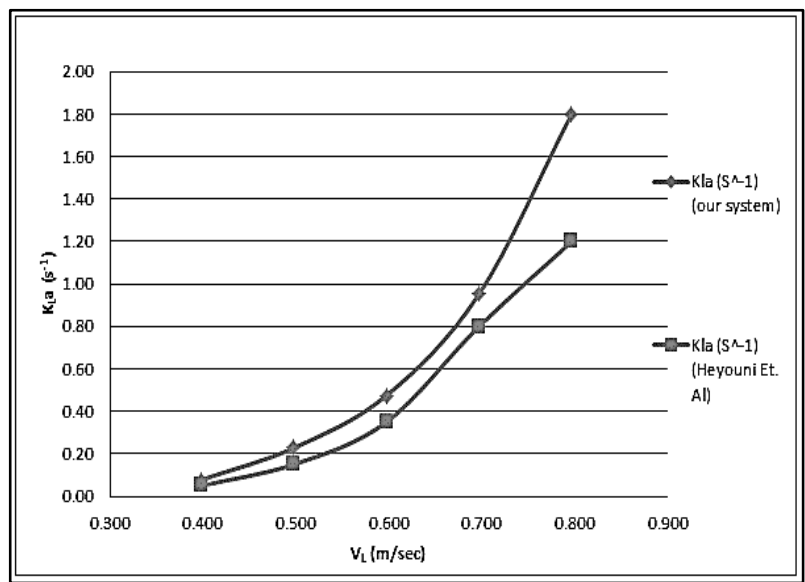

Figure 8: Comparative Study of Mass Transfer Coefficient $\left(\mathrm{K}_{\mathrm{L}} \mathrm{a}\right) \mathrm{using}$ Baffle-Type Element with that of proposed system [14]

During the manipulation of the data collected through the series of experiments conducted with different velocities of water and air, the system model of $\mathrm{K}_{\mathrm{L}}$ a comes out be the following:

$$
\mathrm{K}_{L} \mathrm{a}=12.20 * 10^{-4} \times V_{L}^{1.51} \times V_{G}^{-0.26}
$$

Likewise DO content and air bubble diameter, $\mathrm{K}_{\mathrm{L}} \mathrm{a}$ was also compared with that of the system developed by Heyouni and associates as shown in Figure 8, which clearly shows the higher $\mathrm{K}_{\mathrm{L}}$ a as compared to that of proposed system [14] and [15].

\section{Approximate Bubble Diameter-A Mathematical Hint}

As discussed above also, the bubble size depends amongst various parameters on mass transfer in dimensionless number as proposed by Legrand and associates shown by the following equation:

$$
d / d_{p}=K W e^{a} \cdot R e^{b}
$$

Where:

$$
\begin{aligned}
& \text { Weber number }=\frac{\text { Inertial Forces }}{\text { Surface Tension Forces }} \\
& \text { Reynolds number }=\frac{\text { Inertial Forces }}{\text { Viscous Forces }}
\end{aligned}
$$

This standard equation (A) was used to generate the 'System Equation' of bubble diameter in which constants i.e., $K, a$ and $b$ were determined at different optimum Reynold's numbers and Weber's numbers at different velocities of air and water.

Taking " $\ln$ "on both sides:

$$
\ln \left(\frac{d}{d_{p}}\right)=\ln K+a \ln \left(W_{e}\right)+b \ln \left(R_{e}\right)
$$

Where:

$a, b$ and $K$ are constants to be found from experiments. $d=$ Approximate diameter of bubble measured through experiments.

$d_{p}=$ Nozzle diameter through which air is flowing.

First set of data was set in which the flow rates of the water were set as 3000,3500 and $3900 \mathrm{gal} / \mathrm{hr}$. and air flow rates were set as 10, 15 and $20 \mathrm{lit} / \mathrm{min}$. Using these flow rates of water and air, Weber numbers (We) and Reynolds numbers ( $\mathrm{Re})$ were calculated to generate the below equations Eq. [4], Eq. [5] and Eq. [6]. The bubble diameters " $d$ " was taken the same as measured from the "Bubble Visualizing Cell" at these flow rates of water and air. Below are some mathematical calculations to determine the "System Equation" of the bubble diameter i.e., Eq. [B].

$$
\begin{gathered}
\ln (0.1115)=\ln K+a \ln (110.5)+b \ln (31511.41) \\
\rightarrow-2.193=\ln K+4.705 a+10.358 b \\
\ln (0.1635)=\ln K+a \ln (200)+b \ln (42354.15) \\
\rightarrow-1.810=\ln K+5.735 a+10.873 b \\
\ln (0.1363)=\ln K+a \ln (309.82)+b \ln (52753.9) \\
\rightarrow-1.992=\ln K+5.298 a+10.653 b
\end{gathered}
$$

By simultaneously solving Eq. [4], Eq. [5] and Eq. [6], the following values of constants were determined: 


$$
\begin{aligned}
& a=-4.61 \\
& b=10 \\
& K=3 \times 10^{-37}
\end{aligned}
$$

Where:

subscript 1 is for set 1 data

So for $1^{\text {st }}$ set of equation (A) becomes:

$$
d / d_{p}=3 \times 10^{-37}(W e)^{-4.61} \cdot(R e)^{10}
$$

\section{MASS TRANSFER AREA}

The gas liquid interfacial area $\left(\mathrm{m}^{2} / \mathrm{m}^{3}\right.$ of liquid) is an important parameter for the design in which dispersion occurs. This parameter influences the 'Volumetric Mass Transfer Coefficient'. In the case of a static mixer, the value of interfacial area is greater than that obtained with an empty pipe. This is due to the high energy content required inside the static mixer.

The value of mass transfer area "a" $\left(\mathrm{m}^{2} / \mathrm{m}^{3}\right)$ was thus calculated using following modal equation:

$$
\mathrm{a}=2990 \times V_{L}^{0.01} \times V_{G}^{0.9}
$$

\section{CONCLUSION}

The major objective of this experimental study was to have an optimal design of static mixer element called as Baffle-Type, with the use of which the Hydrodynamic characteristics of mixing fluids can be enhanced using the 'Static Mixing' technique of Air-Water system. A comparative study was done using different types of static elements and different hydrodynamic characteristics were studied e.g., Pressure Reduction across the Static Elements, Dissolved Oxygen (DO) Content / Air Bubble Size, Mass Transfer Coefficient $\left(\mathrm{K}_{\mathrm{L}} \mathrm{a}\right)$, Mass Transfer Area.

Following deductions were carried out from this study: Pressure reduction across the Baffle-Type element was observed more in comparison with other elements due to more mass transfer of air bubbles into the water.

Due to symmetrical geometry of Baffle-Type static element, the reduction in air bubble size was more as compared with that of the use of other elements. This benefit of symmetrical geometry of baffle element leads towards the usage of less elements ( 3 elements of Baffle elements as compared to 42 elements in Lightnin Static Mixer).

The rapid reduction in air bubble size clearly depicts the increase of DO content, for which, when the BaffleType element was compared with other static elements, it comes out to be significantly more $(4.12 \mathrm{mg} / \mathrm{lit})$ with optimal combination of flow rates of fluids i.e. 3900 $\mathrm{gal} / \mathrm{hr}$ (for water) and $20 \mathrm{lit} / \mathrm{min}$ (for air).

Mathematical models were developed for $\mathrm{K}_{\mathrm{L}} \mathrm{a}$ and reduction in air bubble size diameter $\left(d / d_{p}\right)$. The higher rate of DO content with the use of Baffle-Type static element add one more benefit of this system i.e., higher rate of $\mathrm{K}_{\mathrm{L} a}$ as compared with that of the systems available in literature.

\section{Notations}

$\Delta \mathrm{P}=$ Pressure Drop, (bar)

$\mathrm{Re}=$ Reynolds Number $=\left\{\left(\mathrm{ds}^{*} \mathrm{~V}_{\mathrm{L}} * \rho\right) / \mu\right\}$
$\mathrm{We}=$ Weber Number $=\left\{\left(\rho * \mathrm{~V}_{\mathrm{L}}^{2} * \mathrm{~L}\right) / \sigma\right\}$

DO = Dissolved Oxygen (mg/lit)

$\mathrm{V}_{\mathrm{L}}=$ Velocity of Water $(\mathrm{m} / \mathrm{sec})$

$\mathrm{Q}_{\mathrm{L}}=$ Flow Rate of Water $(\mathrm{gal} / \mathrm{hr})$

$\mathrm{V}_{\mathrm{G}}=$ Velocity of Air $(\mathrm{m} / \mathrm{sec})$

$\mathrm{d}=$ Bubble Diameter, $(\mathrm{m})$

$\mathrm{d}_{\mathrm{p}}=$ Nozzle diameter through which air is flowing, $(\mathrm{m})$

$\mathrm{K}_{\mathrm{L}} \mathrm{a}=$ Mass Transfer Coefficient, $\left(\mathrm{s}^{-1}\right)$

$\rho=$ Density of Water, $\left(\mathrm{kg} / \mathrm{m}^{3}\right)$

$\mu=$ Dynamic Viscosity of Water (N.s $\left./ \mathrm{m}^{2}\right)$

$\sigma=$ Surface Tension $(\mathrm{N} / \mathrm{m})$

$\mathrm{L}=$ Length of Static Mixer, (m)

\section{Acknowledgment}

I would like to thanks almighty Allah first and then the management of Sharif College of Engineering and Technology, Lahore, Pakistan, for their support and their assistance throughout this study.

\section{Authors Contributions}

The author, Mazhar Hussain, confirms sole responsibility i.e., study conception and design, data collection, analysis and interpretation of results, manuscript preparation and technical implementation.

\section{Conflict of Interest}

The author declares no conflict of interest and confirms that this work is original and has not been plagiarized from any other source, whether electronic or print media. The information obtained from all of the sources is properly recognized and cited below.

\section{Data Availability Statement}

The testing data is available in this paper.

\section{Funding}

This research work is not funded by any agency/project.

\section{References}

[1] Paglianti, A. (2008). Recent innovations in turbulent mixing with static elements. Recent Patents on Chemical Engineering, 1(1), 8087.

[2] Hirschberg, S., Koubek, R., Moser, F., \& Schöck, J. (2009). An improvement of the Sulzer SMX ${ }^{\mathrm{TM}}$ static mixer significantly reducing the pressure drop. Chemical Engineering Research and Design, 87(4), 524-532.

[3] Madhuranthakam, C. M. R., Pan, Q., \& Rempel, G. L. (2010) Hydrodynamics in Sulzer SMX static mixer with air/water system. Industrial \& Engineering Chemistry Research, 48(2), 719-726.

[4] Hou, J., Qian, G., \& Zhou, X. (2011). Gas-liquid mixing in a multi-scale micromixer with arborescence structure. Chemical Engineering Journal, 167(2-3), 475-482.

[5] Theron, F., \& Le Sauze, N. (2011). Comparison between three static mixers for emulsification in turbulent flow. International journal of multiphase flow, 37(5), 488-500.

[6] Liu, J., Iranshahi, A., Lou, Y., \& Lipscomb, G. (2013). Static mixing spacers for spiral wound modules. Journal of membrane science, 442, 140-148.

[7] Diptendu D. (2015). Pressure drop and mass transfer study in static mixers with gas continuous phase. The Canadian Journal of Chemical Engineering, 80(4), 727-733.

[8] Heyouni, A., Roustan, M., \& Do-Quang, Z. (2002). Hydrodynamics and mass transfer in gas-liquid flow through static mixers. Chemical Engineering Science, 57(16), 3325-3333. 
[9] Munter, R. (2010). Comparison of mass transfer efficiency and energy consumption in static mixers. Ozone: Science \& Engineering, 32(6), 399-407.

[10] Couvert, A., Péculier, M. F., \& Laplanche, A. (2002). Pressure drop and mass transfer study in static mixers with gas continuous phase. The Canadian Journal of Chemical Engineering, 80(4), 727-733.

[11] Haario, H., \& Turunen, I. (1991). The simulation of a co-current bubble reactor. In Proceedings of the Fourth European Conference on Mathematics in Industry (pp. 159-168). Springer, Dordrecht.

[12] Li, X., Zhang, G., Zhao, X., Zhou, J., Du, G., \& Chen, J. (2020). A conceptual air-lift reactor design for large scale animal cell cultivation in the context of in vitro meat production. Chemical Engineering Science, 211, 115269.

[13] Sattari-Najafabadi, M., Esfahany, M. N., Wu, Z., \& Sunden, B. (2018). Mass transfer between phases in microchannels: A review. Chemical Engineering and Processing-Process Intensification, 127, 213-237.

[14] Zaidani, M., Hasan, A., Al-musharfy, M., \& Sassi, M. (2020). Numerical investigation of surface wettability on gas-Liquid flow hydrodynamics in microchannel: Application to trickle bed reactors. Journal of Petroleum Science and Engineering, 184, 106576.

[15] Legrand, J., Morançais, P., \& Carnelle, G. (2001). Liquid-liquid dispersion in an SMX-Sulzer static mixer. Chemical Engineering Research and Design, 79(8), 949-956. 